\title{
Evaluating the Ecology of Tantilla Relicta in Florida Pine-Wiregrass Sandhills Using Multi-Season Occupancy Models
}

\author{
Sky T. Button, ${ }^{1,2}$ Adia R. Sovie, ${ }^{3}$ Cathryn H. Greenberg, ${ }^{4}$ and James D. Austin ${ }^{3}$ \\ ${ }^{1}$ Department of Fish and Wildlife Conservation, Virginia Tech, Blacksburg, Virginia, 24061, USA \\ ${ }^{3}$ Department of Wildlife Ecology and Conservation, University of Florida, Gainesville, Florida, 32611, USA \\ ${ }^{4}$ USDA Forest Service, Southern Research Station, Bent Creek Experimental Forest, 1577 Brevard Road, Asheville, North Carolina, 28806, USA
}

\begin{abstract}
Occupancy modeling may be the most effective tool for studying the occurrence of secretive fossorial squamates. Our objective was to use occupancy models to test whether Florida Crowned Snakes (Tantilla relicta) are a suitable model species for other, more-secretive fossorial squamates. Tantilla relicta are easier to study than other fossorial squamates and likely respond to habitat management (e.g., fire frequency) similarly to these harder-to-study species of concern. We sampled T. relicta using 24 groups of drift fences in longleaf pine-wiregrass sandhills, Ocala National Forest, Florida, USA to assess how habitat characteristics and weather influenced their occupancy, detection, colonization, and extinction rates. We predicted that temperature, rainfall, substrate composition, and prescribed burn history would influence $T$. relicta occupancy, detection, and movement in variable directions. The best-supported multiseason occupancy model included 1) initial occupancy influenced by time since last burn, 2) extinction and colonization as random processes, and 3) detection influenced by percent leaf litter and rainfall. Tantilla relicta were most likely to occupy recently burned sites and were most easily detected during dry periods and at sites with low leaf litter cover. Our results are consistent with research suggesting that short-return prescribed fires benefit many reptile species in central Florida's xeric longleaf pine-wiregrass forests. Further, our results provide modest evidence that $T$. relicta are suitable model organisms for studying fossorial squamate assemblages.
\end{abstract}

Many reptile species are difficult to study because of their cryptic life histories and low detection probabilities. This is particularly true for fossorial species that spend most of their time in inaccessible habitats (Steen, 2010; Willson and Pittman, 2018). Although these reptiles defy conventional study methods, statistical frameworks that account for their low detectability (e.g., occupancy modelling) can create novel opportunities for studying their ecology (Luiselli, 2006; Durso et al., 2011; McGrath et al., 2015). However, occupancy models and other study methods which incorporate detection have been applied to only a few fossorial reptile species (Bailey et al., 2004; Gooch et al., 2006; Luiselli, 2006; Durso et al., 2011), and large knowledge gaps about these species persist.

Research on upland fossorial squamates typifies the challenges associated with cryptic reptiles, which are often difficult to detect using even the most-efficient sampling schemes (Steen et al., 2012a). Several poorly studied fossorial reptile species inhabit longleaf pine-wiregrass upland forests in the southeastern United States (Campbell and Christman, 1982; Ford et al., 1991). These species spend most of their time underground or in other habitats inaccessible to researchers, often precluding indepth studies of their ecology and habitat needs (Steen, 2010; Steen et al., 2012a). Previous studies have succeeded in studying the ecology of large-bodied upland squamates using statistical frameworks that account for imperfect detection (Steen et al., 2012b). However, smaller-bodied members of this assemblage have often been ignored, and it remains unknown how much sampling effort is necessary to detect these species when they are present. Studying the most-easily detectable members of this assemblage using occupancy models may serve as a useful starting point for bridging this gap. Estimates of detectability derived from such studies can be viewed as best-case estimates of how much effort, at a minimum, is needed to study more-

\footnotetext{
${ }^{2}$ Corresponding Author. Present address: Department of Wildlife Ecology and Conservation, University of Florida, Gainesville, Florida, 32611, USA. E-mail: sbutton@vt.edu

DOI: $10.1670 / 18-112$
}

cryptic or rare species and may help inform sampling schemes for studying more-cryptic or rare members of this assemblage.

Florida Crowned Snakes (Tantilla relicta) are an excellent candidate species for developing such minimum estimates of small-bodied fossorial squamate detectability. Tantilla relicta are sympatric with several other ecologically similar squamates (e.g., Lampropeltis extenuata [Short-Tailed Snake], Plestiodon reynoldsi [Florida Sand Skink], and Rhineura floridana [Florida Worm Lizard]) but are presumably more common (Mushinsky and Witz, 1993). Tantilla are captured in drift fence pitfall traps at rates $100 \times$ those of similar squamates in suitable upland habitat (Greenberg, unpubl. data), a difference likely not explained by differential detection probabilities alone. Like several other fossorial squamates, they live in longleaf pinewiregrass uplands and are most easily sampled using drift fences and pitfall traps (Mushinsky and Witz, 1993; Greenberg et al., 1994; Enge, 2001). Tantilla relicta may also represent a suitable model species for evaluating the ecology of secretive fossorial squamate assemblages because they are relatively easy to study and are an important prey item of some other assemblage members (Godley et al., 2008). Other fossorial upland species tend to be associated with recently burned areas (Mushinsky, 1985; Greenberg, 1994) and are generally thought to be surface-active before or after rainfall (Howze and Smith, 2012; Enge, 2014; Lillywhite, pers. comm.). If they are a suitable model species, Tantilla relicta should also occur at recently burned sites and be more surface active in conjunction with rainfall. Tantilla relicta surface activity patterns should be inferable from patterns of detectability using pitfall traps because captures in these traps are a direct result of surface movements.

Given the potential for studies of T. relicta to yield inferences about upland fossorial snake assemblages, it is desirable to have estimates of their detectability and habitat preferences. The detectability and site occupancy of cryptic species can be estimated using occupancy models (MacKenzie et al., 2002; MacKenzie and Bailey, 2004). Briefly, these models assume demographic closure or random changes in occupancy within 


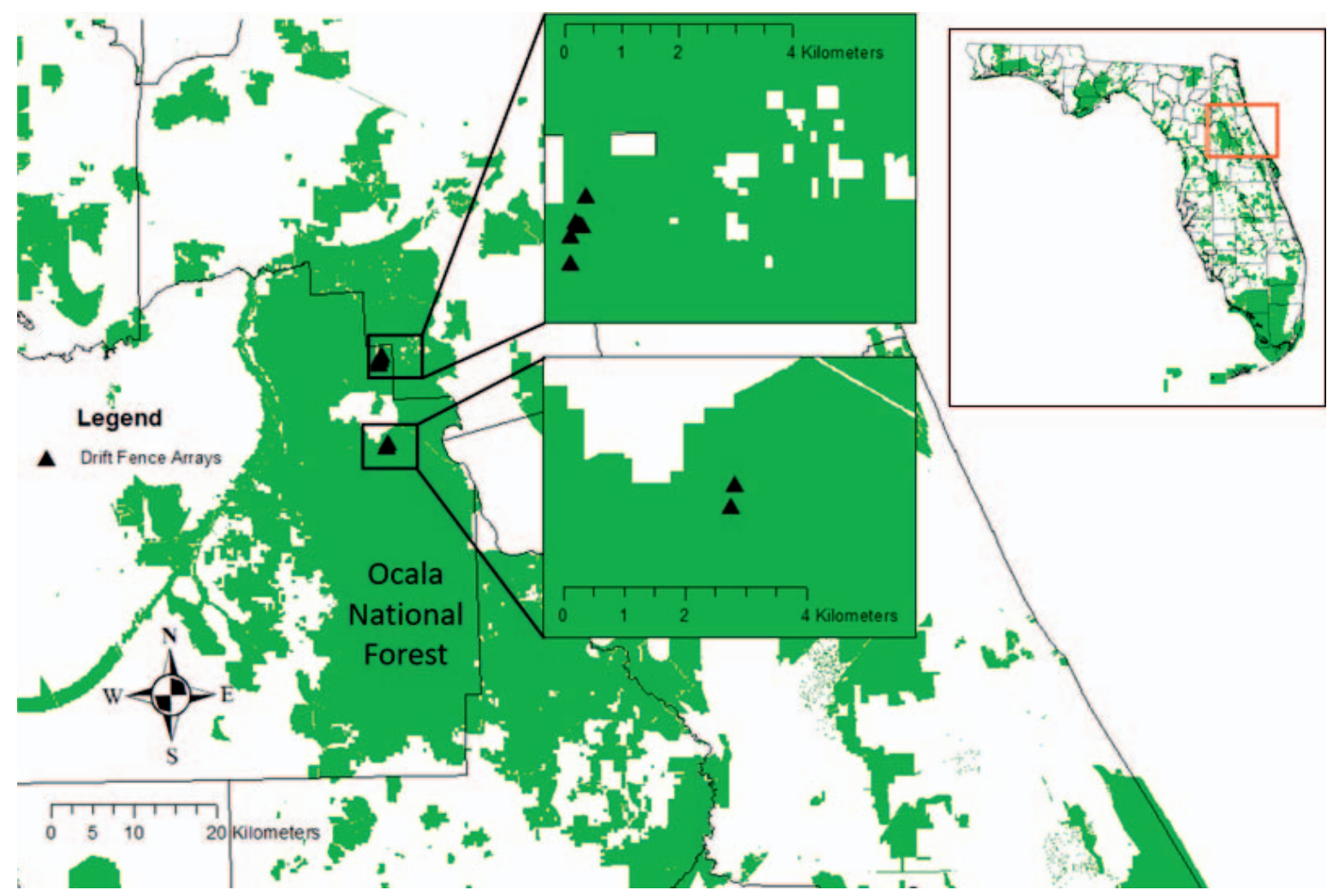

FIG. 1. Locations of drift fence arrays used to capture T. relicta in Ocala National Forest, USA. Green areas represent protected areas, including Ocala National Forest. Triangles indicate study ponds with drift fence arrays. We treated $2-4$ drift fence triplets (total $n=24$ ) at each pond as sites in our analysis.

"primary periods" consisting of multiple samples and use detection/nondetection data within these periods to estimate detectability and site occupancy. Multiseason occupancy models allow for multiple primary periods, provide estimates of colonization and extinction between these periods (MacKenzie et al., 2003), and are useful for determining how a species is moving into and out of selected study sites. Using a multiseason occupancy modeling framework, we sought to determine 1) the minimum amount of effort necessary to declare T. relicta absent with a $95 \%$ confidence interval (CI) using pitfall traps, 2) which physical and environmental characteristics maximize $T$. relicta detectability and site occupancy, 3) the appropriateness of treating $T$. relicta as a model species for other small-bodied fossorial squamates in future studies, given their habitat preferences and surface activity patterns, and 4) how often $T$. relicta site occupancy changes over time.

We hypothesized that $T$. relicta should be less surface-active (i.e., detectable) during rainy periods and at sites with high percentages of leaf litter/pine straw cover. Rain is known to hinder short-term fossorial snake surface activity in the Southeastern Coastal Plain, potentially because snakes in this region have limited sensory perception while surface active during rainfall (Eskew and Todd, 2017) or because the top layer of well-drained sandy soils in this region is only briefly inundated with water following light or moderate precipitation (Brady and Weil, 2008). Further, substrate compaction seems likely to reduce how easily $T$. relicta can move below the surface, thus avoiding capture in pitfall traps. As frequent prescribed fires benefit fauna in central Florida's longleaf pine-wiregrass forests (Mushinsky, 1985; Greenberg, 1994), we hypothesized that $T$. relicta would occupy recently burned sites more often.
Finally, we predicted that rainfall and temperature over 8-wk periods would drive $T$. relicta colonization and extinction rates because both are known to affect snake surface activity (in either positive or negative directions depending on species; Mertens, 1994; How and Shine, 1999; Howze and Smith, 2012; Nordberg and Cobb, 2017) and also drive long-term changes in snake habitat suitability (Penman et al., 2010).

\section{Materials AND Methods}

Study Area.-Between 1 February 2014 and 30 June 2015, we sampled $T$. relicta using drift fence arrays at eight locations in pine-wiregrass upland savanna (Fig. 1). We designed trapping arrays to capture amphibians; thus, we located them in terrestrial habitat adjacent to eight small (0.10-0.37 ha), ephemeral, groundwater-driven sinkhole wetlands. These wetlands were embedded within xeric longleaf pine-wiregrass uplands of the Floridan Aquifer System region, Ocala National Forest, Marion and Putnam Counties, Florida (Fig. 1; Greenberg et al., 2015). During the study period, average weekly temperatures ranged from $11^{\circ} \mathrm{C}$ in December to $30^{\circ} \mathrm{C}$ in August. Total yearly rainfall $(1$ February 2014 to 31 January 2015) at our study areas was 184.1 $\mathrm{cm}$, with more than half occurring during late spring and summer. Heavy precipitation was associated with thunderstorms and tropical systems in summer and fall, and wet autumn, winter, or spring frontal systems (Winsberg, 1990). The average recency of prescribed fire during our study varied between 410 and 6,927 d across our eight study locations.

Field Methods.-We utilized the straight-line drift fence design and trapping methods described by Greenberg et al. $(2015,2017)$. In brief, we placed four pitfall traps (19-L buckets) at the ends of 
$7.8 \mathrm{~m}$-long straight-line aluminum fences that were equally, intermittently spaced to encircle $50 \%$ of each pond's circumference. Our traps were effective for capturing several small-bodied amphibian and reptile species, consistent with observations by Enge (2001). We have observed small squamates falling into pitfall traps on several occasions, but have never seen individuals slowing down or stopping upon approaching a trap (Button, pers. obs.), suggesting that they do not notice the traps and therefore cannot intentionally avoid them. We checked traps three times per week during spring, summer, and early fall, and 1-2 times per week (or more during unseasonably warm temperatures or following heavy rainfall) during late fall and winter when capture rates were negligible. After capturing $T$. relicta, we marked them by scale-clipping and released them within 1-2 $\mathrm{m}$ of their original capture location. We monitored rainfall using a rain gauge and the temperature using a thermometer. At the end of the study we categorized the habitat structure surrounding each drift fence. Using a modified Daubenmire (1959) classification method, we visually categorized percent bare ground, percent leaf litter/pine straw, and percent grasses and forbs within a 2-m buffer of each straight-line drift fence into 10 classes $(1=0-10 \%, 2=11-20 \%, 3=2-30 \%$, etc.). We estimated substrate composition at the end of the study because removal and trampling of vegetation within $\sim 0.5 \mathrm{~m}$ of fences was common during normal sampling activity. Changes in substrate composition across the duration of this study were generally minor because of its relatively short time span (17 mo) and because of a lack of fire and other major disturbances during the study period.

Data Processing.-The performance of occupancy models increases as the number of spatial replicates and naïve occupancy rates increase (MacKenzie and Bailey, 2004). Therefore, we sought to break our 8 drift fence arrays (each consisting of 9 to 16 individual drift fences) into smaller units to maximize model performance. We initially attempted to treat every drift fence as its own replicate, but Moran's I Correlograms (Dormann et al., 2007) indicated that detection/nondetection data at adjacent drift fences were spatially autocorrelated and that naïve occupancy at individual fences was too low for occupancy models to produce meaningful results. We ultimately chose to treat groups of three adjacent drift fences (fence triplets) as individual replicates in our analyses because doing so increased naïve occupancy to satisfactory levels. We randomly designated 2-4 equally spaced fence triplets as replicates within each of our eight drift fence arrays, resulting in 24 total replicates. We spaced replicates $>25$ $\mathrm{m}$ apart (Fig. 2) because detection/nondetection data were not autocorrelated beyond $25 \mathrm{~m}$ and because small-bodied squamates do not often move beyond such distances across short periods (Barbour et al., 1969; Webb and Shine, 1997; How and Shine, 1999; Hill and Fitzgerald, 2007). Several drift fences could not be incorporated into a replicate without violating the need to space replicates $>25 \mathrm{~m}$ apart, so we discarded data from those fences (Fig. 2). Each replicate (fence triplet) covered an area of approximately $500 \mathrm{~m}^{2}$. We pooled estimates of substrate composition across the three fences within each replicate to determine overall substrate composition at each replicate. We also calculated average days since last burn at each replicate across the duration of the study using existing data on when prescribed burns were conducted at each of our eight drift fence arrays (United States Forest Service, unpubl. data). To improve model performance, we $z$-scaled fire history prior to analysis.

Multiseason occupancy models assume demographic closure (or random changes in occupancy) and repeated sampling

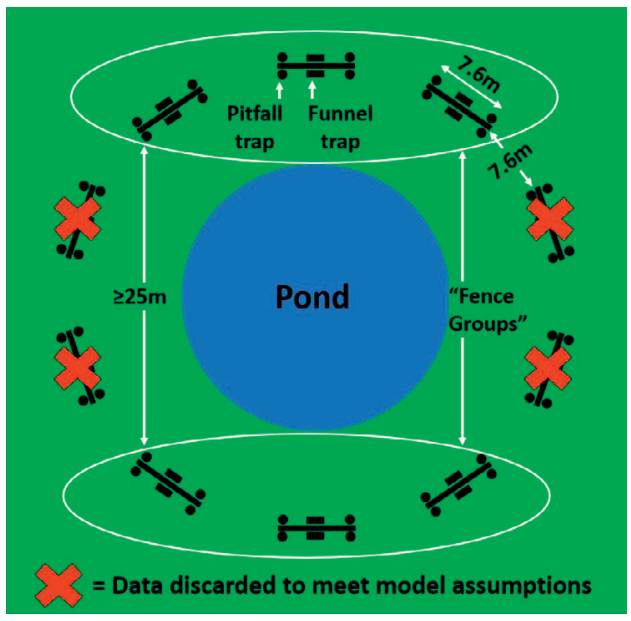

Fig. 2. Design of T. relicta drift fence arrays in Ocala National Forest, USA, and method for designating multiple, independent sites around the same pond. We spaced all sites at least $25 \mathrm{~m}$ apart because spatial autocorrelation was negligible at this distance.

("secondary periods") within short-term "primary periods" but they do permit changes in occupancy between these periods. We used month-long primary periods each containing four, 1-wk secondary periods. We sampled $T$. relicta during six primary periods spaced $8 \mathrm{wk}$ apart (24 total secondary periods; total effort $=48,384$ trap nights). We formatted sampling data within each week by collapsing $T$. relicta detection/nondetection data at each replicate across site visits $(n=1-3)$ within the same week into a single detection/nondetection measure for the week (i.e., we considered T. relicta to have been "detected" at a replicate within a given week if we captured any individuals at that replicate on at least one occasion during that week). We used 4-wk primary periods because nonrandom $T$. relicta movements into and out of replicates seemed unlikely during such periods given the low movement rates typical in fossorial squamates (Barbour et al., 1969; Webb and Shine, 1997; How and Shine, 1999; Hill and Fitzgerald, 2007). Spacing primary periods only 8 wk apart allowed us to minimize the amount of between-period data that needed to be discarded, while still allowing for nonrandom changes in site occupancy between primary periods based on conservative estimates of small squamate movements (Barbour et al., 1969; Macartney et al., 1988).

Data Analysis.-We built multiseason occupancy models (MacKenzie et al., 2003) using the package 'unmarked' in R (Fiske and Chandler, 2011; Version 3.3.3, R Core Development Team). Unmarked uses detection/nondetection data from individual surveys (secondary periods) to estimate detection probability and combines naïve occupancy estimates (proportion of sites with at least one detection event within each primary period) with estimated detection probabilities to predict initial site occupancy. Colonization and extinction parameters estimate changes from initial occupancy that occur between primary periods.

We tested temperature and rainfall data within primary periods as detection covariates in our models and as colonization and extinction covariates between primary periods. We performed a principle components analysis (PCA) on temperature variables (minimum temperature, mean temperature, maximum temperature) within secondary sampling periods to minimize variable redundancy while also minimizing the potential for overfitting models with too many covariates. We used an orthogonal factor incorporating minimum, maximum, and mean temperature instead of selecting one metric and discarding the other two. For 


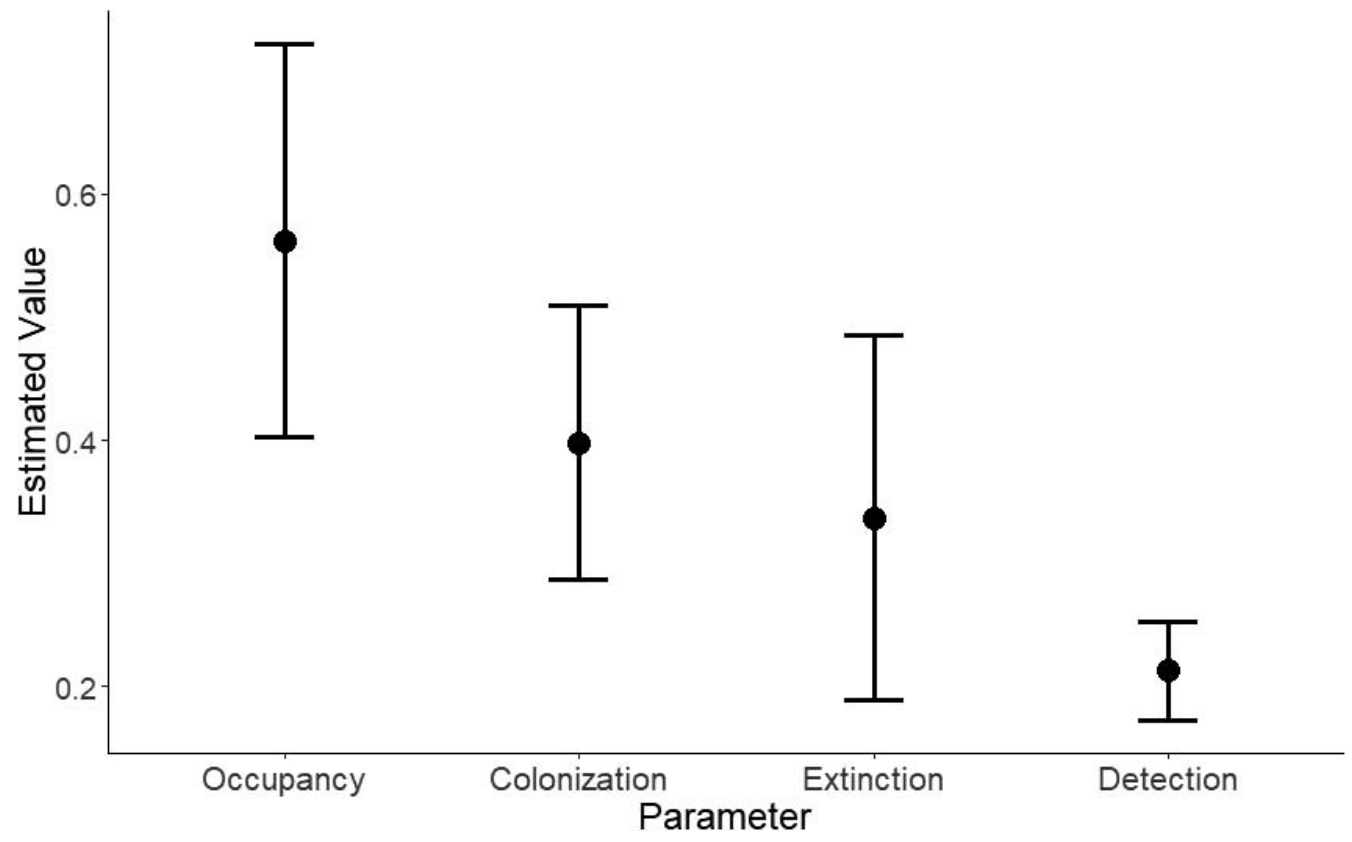

Fig. 3. Estimates of average T. relicta occupancy, colonization, extinction, and detection rates across the course of our study in Ocala National Forest, USA. Error bars show standard errors.

each secondary period we used the first orthogonal factor (F1, $93.99 \%$ variability explained) as a covariate in our analyses of detection probability. We did not include rainfall in this PCA because it was relatively uncorrelated with all temperature metrics within primary periods. We also performed a PCA on all weather measurements taken during 8-wk gaps between primary periods and used the first orthogonal factor (F1, 90.17\% variability explained) as a covariate for modeling colonization and extinction. In addition to temperature variables, we also tested percent leaf litter, bare ground, and recency of prescribed fire (in days) as occupancy covariates in our models. We chose not to test percent grass/forb cover as an occupancy covariate because it was highly correlated with percent leaf litter. We $z$-scaled all variables prior to analysis. It was unnecessary to incorporate spatial eigenvectors into our models as covariates or to spatialize our predictors (Huang and Frimpong, 2015) because detection/nondetection data showed no signs of spatial autocorrelation and, therefore, were not driven by spatial autocorrelation present in any predictor variables.

We built models using the stepwise procedure described by Burnham and Anderson (2003). This procedure increases model complexity at each step and consists of first building models for detection probability while holding all other parameters constant. Occupancy terms are added to the best-performing of these initial models, which are ranked using Akaike's Information Criterion (AIC; Akaike, 1998). Colonization and extinction terms are later added to the best-performing of these models. We built 13 total models using this procedure, based on biological hypotheses about $T$. relicta movement rates, habitat preferences, and detectability. We used a null model to derive estimates of average detectability and site occupancy, colonization, and extinction. We then used the null model estimate of detectability to estimate the amount of effort (trap nights and number of unsuccessful visits using our sampling scheme) necessary to declare $T$. relicta absent from a site with $95 \%$ confidence (McArdle, 1990). We defined a trap night as the passage of a single night at a single pitfall trap.

\section{RESULTS}

We captured at least one T. relicta during 66 of 576 total possible secondary periods across our 24 fence triplets $(48,384$ trap nights). Null model estimates of overall detection, occupancy, colonization, and extinction were 0.213 (95\% CI: $0.135,0.291), 0.562$ (95\% CI: 0.250, 0.874), 0.398 (95\% CI: 0.180, 0.616 ), and 0.337 (95\% CI: 0.047, 0.627), respectively (Fig. 3). Our null model estimate of detection suggests that it is necessary to make 12.57 "visits" (equivalent to 1,056 trap nights) within a 4wk period to declare $T$. relicta absent from sites of our size with 95\% confidence. Our top-ranked model included percent leaf litter cover and rainfall as detection covariates, recency of last burn as an initial occupancy covariate, and colonization and extinction as random processes (Fig. 4; Table 1). Tantilla relicta occupied recently burned sites more often during our study, but the $95 \%$ CI crossed 0 ( $\beta=-5.790 ; 95 \%$ CI: $-49.106,37.526)$. Our top model suggested that high leaf litter cover decreased $T$. relicta detection (Fig. $2 ; \beta=-0.531 ; 95 \%$ CI: $-0.837,-0.225$ ). Increased rainfall over the preceding week also decreased detection (Fig. 2; $\beta=-0.344 ; 95 \%$ CI: $-0.654,-0.034$ ). Temperature appeared to have negligible influence on detectability, and its inclusion weakened model performance. We also found no evidence that our weather variables collectively influenced colonization or extinction at our study sites across 8-wk periods (Table 1).

\section{DisCUSSION}

Low capture rates of $T$. relicta are likely a function of low detectability rather than rarity (Mushinsky and Witz, 1993). We estimated high site occupancy (0.562), although $T$. relicta was only captured during $11.4 \%$ of week-long secondary periods across all 24 sites. Our estimate of $T$. relicta detection probability (0.213) is relatively low compared to other herpetofauna (Bailey et al., 2004; Gooch et al., 2006; Durso et al., 2011; Rodda et al., 2015), supporting the idea that upland fossorial squamates are exceptionally difficult to sample. Steen et al. (2012a) found, 
TABLE 1. Models of T. relicta occupancy $(\Psi)$, detection probability $(p)$, colonization $(\gamma)$, and extinction $(\varepsilon)$. Models were built using a stepwise procedure (Burnham and Anderson, 2003) and ranked by AIC. Rain = rainfall; Temp $=$ F1 from PCA of minimum, maximum, and mean temperatures within each primary period; $\mathrm{LL}=$ percent leaf litter cover; $\mathrm{BG}=$ percent bare ground cover; Fire $=$ average days since last prescribed burn; WX (Weather) = F1 of temperature and rainfall PCA constructed using data between primary periods.

\begin{tabular}{|c|c|c|c|}
\hline Model & AIC & $\Delta \mathrm{AIC}$ & $\mathrm{w}_{\mathrm{i}}$ \\
\hline \multicolumn{4}{|l|}{ Step 1} \\
\hline$\Psi(.) \gamma(.) \varepsilon() p.(\mathrm{LL}+$ Rain $)$ & 399.13 & 0.00 & 0.729 \\
\hline$\Psi(.) \gamma(.) \varepsilon() p.(\mathrm{LL})$ & 402.06 & 2.93 & 0.169 \\
\hline$\Psi(.) \gamma(.) \varepsilon() p.($ Rain $)$ & 403.85 & 4.72 & 0.069 \\
\hline$\Psi(.) \gamma(.) \varepsilon() p.(\mathrm{BG})$ & 407.26 & $8.1 \overline{3}$ & 0.013 \\
\hline$\Psi(.) \gamma(.) \varepsilon() p.()$. & 407.53 & 8.40 & 0.011 \\
\hline$\Psi(.) \gamma(.) \varepsilon() p.($ Fire) & 408.94 & 9.81 & 0.005 \\
\hline$\Psi(.) \gamma(.) \varepsilon() p.($ Temp) & 409.44 & 10.31 & 0.004 \\
\hline \multicolumn{4}{|l|}{ Step 2} \\
\hline$\Psi($ Fire $) \gamma(.) \varepsilon() p.($ LL + Rain $)$ & 395.20 & 0.00 & 0.743 \\
\hline$\Psi(\mathrm{BG}) \gamma(.) \varepsilon() p.(\mathrm{LL}+$ Rain $)$ & 399.09 & 3.89 & 0.106 \\
\hline$\Psi(.) \gamma(.) \varepsilon() p.(\mathrm{LL}+$ Rain $)$ & 399.13 & 3.93 & 0.104 \\
\hline$\Psi(\mathrm{LL}) \gamma(.) \varepsilon() p.(\mathrm{LL}+$ Rain $)$ & 400.75 & 5.55 & 0.046 \\
\hline \multicolumn{4}{|l|}{ Step 3} \\
\hline$\Psi(\mathrm{LL}) \gamma(.) \varepsilon() p.(\mathrm{LL}+$ Rain $)$ & 395.20 & 0.00 & 0.476 \\
\hline$\Psi(\mathrm{LL}) \gamma(\mathrm{WX}) \varepsilon() p.(\mathrm{LL}+$ Rain $)$ & 396.72 & 1.52 & 0.223 \\
\hline$\Psi(\mathrm{LL}) \gamma(.) \varepsilon(\mathrm{WX}) p(\mathrm{LL}+$ Rain $)$ & 396.76 & 1.56 & 0.218 \\
\hline$\Psi(\mathrm{LL}) \gamma(\mathrm{WX}) \varepsilon(\mathrm{WX}) p(\mathrm{LL}+$ Rain $)$ & 398.71 & 3.51 & 0.082 \\
\hline \multicolumn{4}{|l|}{ All Models } \\
\hline$\Psi(\mathrm{LL}) \gamma(.) \varepsilon() p.(\mathrm{LL}+$ Rain $)$ & 395.20 & 0.00 & 0.400 \\
\hline$\Psi(\mathrm{LL}) \gamma(\mathrm{WX}) \varepsilon() p.(\mathrm{LL}+$ Rain $)$ & 396.72 & 1.52 & 0.188 \\
\hline$\Psi(\mathrm{LL}) \gamma(.) \varepsilon(\mathrm{WX}) p(\mathrm{LL}+$ Rain $)$ & 396.76 & 1.56 & 0.184 \\
\hline$\Psi(\mathrm{LL}) \gamma(\mathrm{WX}) \varepsilon(\mathrm{WX}) p(\mathrm{LL}+$ Rain $)$ & 398.71 & 3.51 & 0.069 \\
\hline$\Psi(\mathrm{BG}) \gamma(.) \varepsilon() p.(\mathrm{LL}+$ Rain $)$ & 399.09 & 3.89 & 0.057 \\
\hline$\Psi(.) \gamma(.) \varepsilon() p.(\mathrm{LL}+$ Rain $)$ & 399.13 & 3.93 & 0.056 \\
\hline$\Psi(\mathrm{LL}) \gamma(.) \varepsilon() p.(\mathrm{LL}+$ Rain $)$ & 400.75 & 5.55 & 0.025 \\
\hline$\Psi(.) \gamma(.) \varepsilon() p.(\mathrm{LL})$ & 402.06 & 6.85 & 0.013 \\
\hline$\Psi(.) \gamma(.) \varepsilon() p.($ Rain $)$ & 403.85 & 8.65 & 0.005 \\
\hline$\Psi(.) \gamma(.) \varepsilon() p.(\mathrm{BG})$ & 407.26 & 12.06 & 0.001 \\
\hline$\Psi(.) \gamma(.) \varepsilon() p.()$. & 407.53 & 12.33 & 0.001 \\
\hline$\Psi(.) \gamma(.) \varepsilon() p.($ Fire) & 408.94 & 13.74 & 0.000 \\
\hline$\Psi(.) \gamma(.) \varepsilon() p.($ Temp) & 409.44 & 14.24 & 0.000 \\
\hline
\end{tabular}

using a larger dataset than our own, that capture rates of medium- and large-bodied upland snakes sampled using box traps were too low to confidently estimate abundance given detection/nondetection data (Royle and Nichols, 2003). While we hesitate to suggest that $T$. relicta population size would be estimable with detection accounted for, our estimates of detection probability are more optimistic than those for the fossorial snake species sampled by Steen et al. (2012a). Pitfall traps may be better at capturing small squamates than box traps are at catching large snakes, consistent with existing literature about pitfall and box trapping efficiencies (Mushinsky and Witz, 1993; Greenberg et al., 1994; Enge, 2001; Steen et al., 2012a). This is an important consideration if any upland snake species is ever to be treated as a model species representative of upland snake communities as a whole because difficult-to-study animals make for poor model species (Fleishman et al., 2005).

Tantilla relicta are likely one of the most common and detectable reptile species in our study area (Mushinsky and Witz, 1993; Greenberg, 1994) and therefore may be the "bestcase scenario" for detecting fossorial squamates within Florida upland pine-wiregrass ecosystems. Given that T. relicta naïve occupancy (0.236) was not far above the minimum suggested threshold of 0.15 for building occupancy models with predictive power (MacKenzie and Bailey, 2004), we suggest that our sampling effort within each primary period (672 trap nights per site) be viewed as a minimum requirement for studies seeking to estimate detection and occupancy trends in fossorial squamates using small spatial scales. Studies concerned with occupancy and detectability trends in small upland fossorial squamates that are more cryptic than $T$. relicta (e.g., L. extenuata, $P$. reynoldsi, and $R$. floridana) should therefore include more traps than our study did within each site and should be designed such that each site is large relative to the species movement rates. This should maximize the number of possible chances to catch fossorial squamates in traps within primary sampling periods and improve naïve occupancy.

Although our data do not translate directly to sampling schemes using box traps to capture larger-bodied upland squamates (often of management concern), these general recommendations may be pertinent for large-bodied upland snake species (e.g., Eastern Pinesnakes [Pituophis melanoleucus], Eastern Diamond-backed Rattlesnakes [Crotalus adamanteus], Eastern Indigo Snakes [Drymarchon couperi], Lampropeltis spp.), which have exceptionally low detectability even in carefully placed box trap arrays (Steen et al., 2012a,b), and cannot be trapped using pitfall traps (Enge, 2001). Our relatively high colonization and extinction estimates $(0.398$ and 0.337 , respectively) across 8 -wk periods suggest that $T$. relicta populations would not be closed within primary periods, had we increased the lengths of these periods. It is difficult to determine whether changes in site occupancy were random across 8-wk periods, given the similar performance of models that used weather as a colonization and/or extinction covariate to models which considered these outputs random. It is important to note that colonization and extinction rates reflect changes in whether a species is available for sampling within a given study area. Tantilla relicta that were available for sampling in one primary period but then moved deep underground (or became otherwise unavailable for sampling) before the next primary period would therefore be considered to have temporarily emigrated from a site (Willson et al., 2011), even if they did not physically exit the area. Given our high predicted rates of colonization and extinction across 8-wk periods, and the tendencies of squamates to disperse during certain favored conditions (Macartney et al., 1988), we find it likely that increasing the length of our primary periods beyond $4 \mathrm{wk}$ would have violated model assumptions of random or no changes in occupancy within these periods. We therefore suggest that occupancy modeling studies of squamates that are more cryptic or vagile than $T$. relicta should use study sites spaced far enough apart and with large enough spatial extents to remain functionally closed and independent over long periods of time.

Detectability of $T$. relicta was inversely correlated with the percentage of leaf litter/pine straw covering the ground at each site (Fig. 4). Although no studies to our knowledge have evaluated the influence of substrate on $T$. relicta surface movements, this result was expected because leaf litter at our study sites tends to be less compact than soil, grasses, and forbs (Button, pers. obs.) and should therefore be easier for T. relicta to move through below the surface, reducing capture probability in pitfall traps. We also predicted that $T$. relicta should be less detectable following periods of rainfall, consistent with surface activity trends known from dozens of coastal plain squamates (Eskew and Todd, 2017) and Australian elapids (How and Shine, 1999; Howze and Smith, 2012; Enge, 2014). Tantilla relicta detection was inversely correlated with rainfall, suggesting support for this hypothesis. Surface activity in T. relicta is likely 

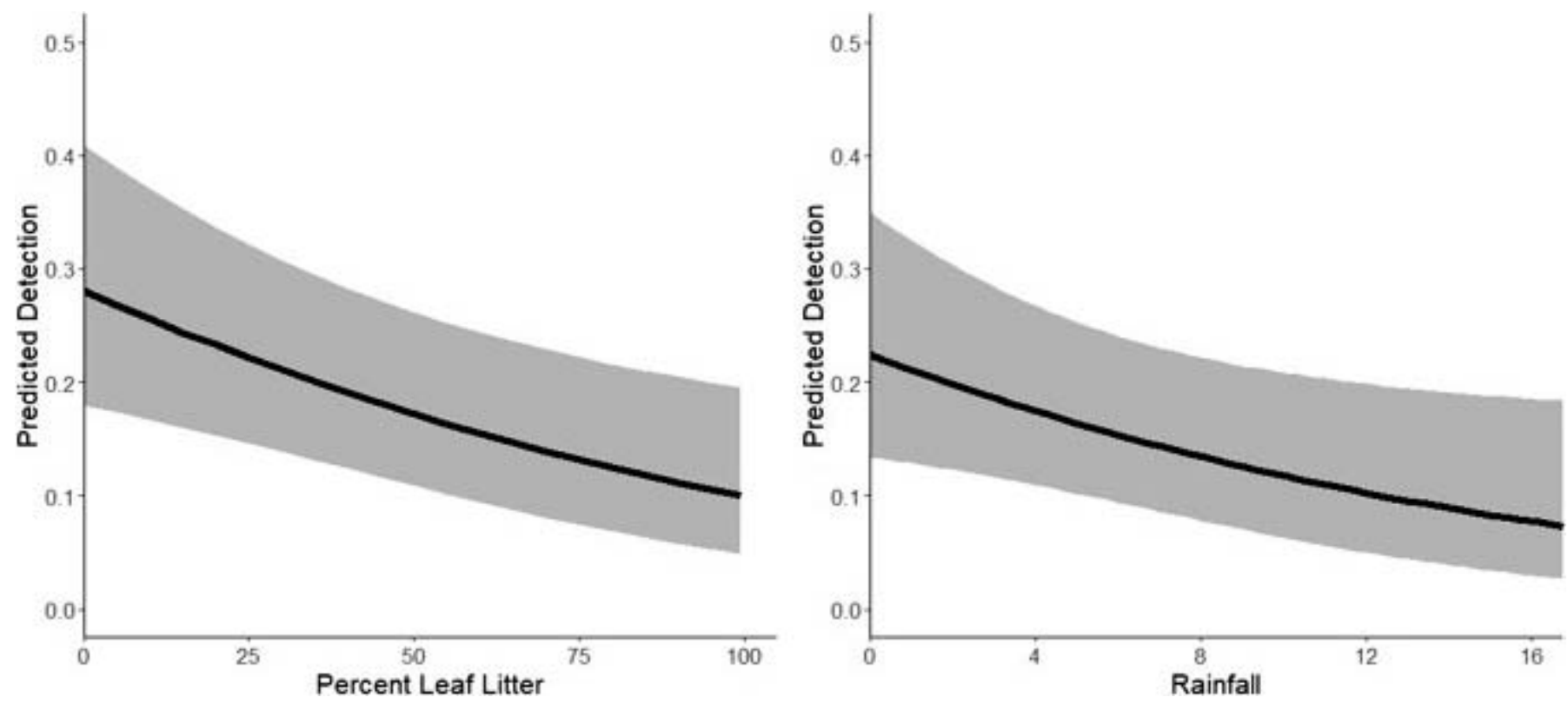

FIG. 4. Influences of rainfall and leaf litter on T. relicta detection probability in Ocala National Forest, USA, taken from the top-performing model. Shaded areas represent $95 \%$ CI. Detectability declines as rainfall and percent leaf litter increase.

sparked by similar conditions (absence of precipitation) to those mediating activity in sympatric, heterospecific squamates, lending credibility to future treatment of the $T$. relicta as a model species. Fossorial invertebrate prey biomass, proximity to the primary breeding season (presumably April-June), and cooccurrence with sympatric squamates may also impact $T$. relicta surface activity and detectability, though these factors are beyond the scope of this study.

We expected that $T$. relicta would be more likely to occupy recently burned sites, consistent with other upland squamates. Although top-performing models supported this hypothesis, model fit was rather weak, and the influence of prescribed fire recency was not supported by the data. This was possibly a consequence of the average number of days since the last fire at our study sites exhibiting a highly bimodal distribution (either $410-800 \mathrm{~d}$ or $>6,000 \mathrm{~d}$ prior to $z$-scaling, capturing the lower and upper ends typical of fire frequency in upland pinewiregrass sandhills), greatly inflating standard errors for predictions made when prescribed fire recency fell between these values. Alternately, T. relicta may prefer or avoid sites that have experienced a fire more recently than $410 \mathrm{~d}$, which our dataset did not include. Nonetheless, including prescribed fire recency improved model performance and was biologically reasonable. Given that recent fire and other forest management practices that expose relatively intact bare ground tend to benefit many reptile species in xeric Florida uplands (Greenberg, 1994), T. relicta may be an appropriate model species for studying habitat needs of reptiles in these ecosystems. However, our data provide no evidence that $T$. relicta prefer sites burned more recently than in the past $410 \mathrm{~d}$. Colonization and extinction did not appear related to weather over 8-wk periods. This is likely a product of the small spatial extent of our study sites (Charbonnel et al., 2014) and the relatively narrow windows between primary periods because short-distance, short-interval animal movements are often largely stochastic (Worton, 1987). This reinforces the necessity of long-term ecological studies for detecting long-term changes in site occupancy. Our finding that predicted colonization and extinction rates were similar was expected because the habitats within and immediately adjacent to each study site were similar. Our sites likely fostered similar densities of $T$. relicta, making weather-driven movement patterns result in roughly equal movement into and out of each site. We find it unlikely that the proximity of our traps to wetlands substantially influenced any of our parameter estimates because we placed encircling trap arrays 20-100 m back from wetland centers in habitats typical of the surrounding uplands.

The exceptionally cryptic habits of fossorial squamates make them notably difficult to study, even for species that are likely common. Our results provide evidence for low detectability of a presumably common species (Mushinsky and Witz, 1993) of fossorial upland snakes in spite of high predicted site occupancy. Difficulties associated with sampling upland fossorial squamates are especially troublesome, given the number of these species that are of management concern, especially in pine-wiregrass sandhills (United States Fish and Wildlife Service List of Threatened and Endangered Species, 2019). Our low detection estimates for T. relicta suggest that significant effort is required for sampling fossorial squamates in these habitats, most of which are more cryptic than our study species. We therefore suggest that our units of effort be viewed as lower limits for the amount of effort necessary to study small-bodied upland fossorial squamates using pitfall traps.

Tantilla relicta detection was inversely correlated with leaf litter cover and rainfall while occupancy was weakly positively correlated with prescribed fire recency. We therefore suggest that $T$. relicta may be a suitable model species for inferring patterns of habitat and weather-driven occupancy, short-term movement patterns, and detectability across upland fossorial squamate communities. Our finding that $T$. relicta colonization and extinction rates were relatively high across 8 -wk periods at our small-area study sites suggests that future research on fossorial upland squamates should seek to maximize the spatial extent and independence of study sites to increase the duration of functional demographic closure and improve the ease of modeling occupancy and detection trends of these cryptic 
species. Such studies might also benefit from considering the potential for prey biomass, reproductive cycles, and the cooccurrence of congeners to influence fossorial squamate detectability and occupancy.

Acknowledgments.-We thank field technicians G. Kamener and C. Hartmann for collecting most of the data used in this paper, along with countless volunteers. We also thank Ocala National Forest staff for helping maintain drift fence arrays by removing fallen trees. This research was approved by the Institutional Animal Care and Use Committee (IACUC; permit no. 004-09WEC) and the Florida Fish and Wildlife Conservation Commission (permit no. LSSC-12-00021A).

\section{Literature Cited}

AKAIKE, H. 1998. Information theory and an extension of the maximum likelihood principle. Pp. 610-624 in S. Kotz and N. Johnson (eds.), Breakthroughs in Statistics. Springer Science \& Business Media, Germany.

Bailey, L. L., T. R. Simons, And K. H. Pollock. 2004. Estimating site occupancy and species detection probability parameters for terrestrial salamanders. Ecological Applications 14:692-702.

Barbour, R. W., M. J. Harvey, and J. W. Hardin. 1969. Home range, movements, and activity of the eastern worm snake, Carphophis amoenus amoenus. Ecology 50:470-476.

Brady, N. C., AND R. R. WeIL. 2008. The Nature and Properties of Soils. Pearson Prentice Hall, USA.

Burnham, K. P., and D. R. Anderson. 2003. Model Selection and Multimodel Inference: A Practical Information-Theoretic Approach. Springer-Verlag, USA.

Campbell, H. W., and S. P. Christman. 1982. The herpetological components of Florida sandhill and sand pine scrub associations. Herpetological Communities 13:163-171.

Charbonnel, A., F. D’ Amico, A. Besnard, F. Blanc, L. Buisson, M. Némoz, AND P. LAFFaILle. 2014. Spatial replicates as an alternative to temporal replicates for occupancy modelling when surveys are based on linear features of the landscape. Journal of Applied Ecology 51:1425-1433.

DAUBENMIRE, R. F. 1959. Canopy coverage method of vegetation analysis. Northwest Science 33:43-64.

Dormann, C. F., J. M. McPherson, M. B. Araújo, R. Bivand, J. Bolliger, G. Carl, R. G Davies, A. Hirzel, W. Jetz, and W. Daniel Kissling. 2007. Methods to account for spatial autocorrelation in the analysis of species distributional data: a review. Ecography 30:609-628.

Durso, A. M., J. D. Willson, AND C. T. WinNE. 2011. Needles in haystacks: estimating detection probability and occupancy of rare and cryptic snakes. Biological Conservation 144:1508-1515.

EnGE, K. 2014. Short-tailed snake reproduction. Threatened and Nongame Management Species Annual Report, Florida Fish and Wildlife Conservation Commission, Fish and Wildlife Research Institute, Wildlife Research Laboratory, Gainesville, Florida, USA.

ENGE, K. M. 2001. The pitfalls of pitfall traps. Journal of Herpetology 35 : 467-478.

Eskew, E. A., AND B. D. TodD. 2017. Too cold, too wet, too bright, or just right? Environmental predictors of snake movement and activity. Copeia 105:584-591.

FisKe, I., AND R. ChANDler. 2011. Unmarked: an R package for fitting hierarchical models of wildlife occurrence and abundance. Journal of Statistical Software 43:1-23.

Fleishman, E., J. R. Thomson, R. Mac Nally, D. D. Murphy, and J. P. Fay. 2005. Using indicator species to predict species richness of multiple taxonomic groups. Conservation Biology 19:1125-1137.

Ford, N. B., V. A. COBB, AND J. Stout. 1991. Species diversity and seasonal abundance of snakes in a mixed pine-hardwood forest of eastern Texas. Southwestern Naturalist 36:171-177.

Godley, J., S. Gonzalez, AND M. Gonzalez. 2008. Stilosoma extenuatum (short-tailed snake). Diet and predation. Herpetological Review 39: 473-474.

Gooch, M. M., A. M. Heupel, S. J. Price, and M. E. Dorcas. 2006. The effects of survey protocol on detection probabilities and site occupancy estimates of summer breeding anurans. Applied Herpetology 3:129-142.
GREENBERG, C. H. 1994. Effect of high-intensity wildfire and silvicultural treatments on reptile communities in sand-pine scrub. Conservation Biology 8:1047-1057.

GreenberG, C. H., D. G. Neary, and L. D. Harris. 1994. A comparison of herpetofaunal sampling effectiveness of pitfall, single-ended, and double-ended funnel traps used with drift fences. Journal of Herpetology 28:319-324.

Greenberg, C. H., S. Goodrick, J. D. Austin, and B. R. Parresol. 2015. Hydroregime prediction models for ephemeral groundwater-driven sinkhole wetlands: a planning tool for climate change and amphibian conservation. Wetlands 35:899-911.

GreenberG, C. H., S. J. Zarnoch, and J. D. Austin. 2017. Weather, hydroregime, and breeding effort influence juvenile recruitment of anurans: implications for climate change. Ecosphere 8:e01789.

Hill, M. T., AND L. A. FitzGerald. 2007. Radiotelemetry and Population Monitoring of the Sand Dune Lizards (Sceloporus arenicolus) During the Nesting Season. Wildlife Report to New Mexico Game and Fish Department, USA.

How, R. A., AND R. SHINE. 1999. Ecological traits and conservation biology of five fossorial 'sand-swimming' snake species (Simoselaps: Elapidae) in south-western Australia. Journal of Zoology 249:269-282.

Howze, J. M., AND L. L. SMITH. 2012. Factors influencing eastern kingsnake diel activity. Copeia 2012:460-464.

HunANG, J., AND E. A. Frimpong. 2015. Using historical atlas data to develop high-resolution distribution models of freshwater fishes. PLoS One 10:e0129995.

LUISELLI, L. 2006. Site occupancy and density of sympatric Gaboon viper (Bitis gabonica) and nose-horned viper (Bitis nasicornis). Journal of Tropical Ecology 22:555-564.

MacartNeY, J. M., P. T. GReGorY, AND K. W. LARSEN. 1988. A tabular survey of data on movements and home ranges of snakes. Journal of Herpetology 22:61-73.

MacKenZie, D. I., and L. L. Bailey. 2004. Assessing the fit of siteoccupancy models. Journal of Agricultural, Biological, and Environmental Statistics 9:300-318.

MacKenzie, D. I., J. D. Nichols, G. B. Lachman, S. Droege, J. Andrew Royle, AND C. A. LANGTimm. 2002. Estimating site occupancy rates when detection probabilities are less than one. Ecology 83:2248-2255.

MacKenzie, D. I., J. D. Nichols, J. E. Hines, M. G. KnUtson, and A. B. FRANKLIN. 2003. Estimating site occupancy, colonization, and local extinction when a species is detected imperfectly. Ecology 84:22002207.

McARdLE, B. H. 1990. When are rare species not there? Oikos 57:276-277.

McGrath, T., G. Guillera-Arroita, J. J. Lahoz-Monfort, W. Osborne, D. Hunter, AND S. D. SARRE. 2015. Accounting for detectability when surveying for rare or declining reptiles: turning rocks to find the grassland earless dragon in Australia. Biological Conservation 182: $53-62$.

MERTENS, D. 1994. Some aspects of thermoregulation and activity in freeranging grass snakes (Natrix natrix L.). Amphibia-Reptilia 15:322326.

MUSHINSKY, H. R. 1985. Fire and the Florida sandhill herpetofaunal community: with special attention to responses of Cnemidophorus sexlineatus. Herpetologica 41:333-342.

MushinSKY, H. R., AND B. W. WITZ. 1993. Notes on the peninsula crowned snake, Tantilla relicta, in periodically burned habitat. Journal of Herpetology 27:468-470.

NORDBERG, E. J., AND V. A. COBB. 2017. Body temperatures and winter activity in overwintering timber rattlesnakes (Crotalus horridus) in Tennessee, USA. Herpetological Conservation and Biology 12:606615.

Penman, T. D., D. A. Pike, J. K. Webb, and R. Shine. 2010. Predicting the impact of climate change on Australia's most endangered snake, Hoplocephalus bungaroides. Diversity and Distributions 16:109-118.

Rodda, G. H., K. Dean-Bradley, E. W. Campbell, T. H. Fritts, B. Lardner, A. A. Y. AdAmS, AND R. N. ReED. 2015. Stability of detectability over 17 years at a single site and other lizard detection comparisons from Guam. Journal of Herpetology 49:513-521.

Royle, J. A., AND J. D. Nichols. 2003. Estimating abundance from repeated presence-absence data or point counts. Ecology 84:777-790.

SteEN, D. A. 2010. Snakes in the grass: secretive natural histories defy both conventional and progressive statistics. Herpetological Conservation and Biology 5:183-188.

SteEn, D., C. GuYer, AND L. SMith. 2012a. Box 9: relative abundance in snakes: a case study. Pp. 287-294 in E. McDiarmid (ed.), Reptile Biodiversity: Standard Methods for Inventory and Monitoring. University of California Press, USA. 
Steen, D. A., C. J. W. McLure, J. C. Brock, D. C. Rudolph, J. B. Pierce, J. R. Lee, W. J. Humphries, B. B. Gregory, W. B. Sutton, L. L. Smith, et al. 2012b. Landscape-level influences of terrestrial snake occupancy within the southeastern United States. Ecological Applications 22: 1084-1097.

United States Fish and Wildlife Service. 2019. Threatened and endangered animals: an online reference [Internet]. Available at https: / / www.ecos.fws.gov/ecp0/reports/ad-hoc-species-report? kingdom $=V \&$ kingdom $=I \&$ status $=$ E\&status $=T \&$ status $=$ EmE\&status $=$ EmT\&status $=$ EXPE\&status $=$ EXPN\&status $=S A E \& s t a t u s=S A T \&$ fcrithab $=$ on \&fstatus $=$ on $\&$ fspecrule $=$ on $\&$ finvpop $=$ on $\&$ fgroup $=$ on $\&$ header=Listed+Animals. Accessed 31 July 2019.

WeBB, J. K., AND R. ShINE. 1997. A field study of spatial ecology and movements of a threatened snake species, Hoplocephalus bungaroides. Biological Conservation 82:203-217.
Willson, J. D., AND S. PitTMAn. 2018. Innovative Methods for Estimating Densities and Detection Probabilities of Secretive Reptiles Including Invasive Constrictors and Rare Upland Snakes. Technical Report. University of Arkansas, USA.

Willson, J. D., C. T. WinNe, AND B. D. TodD. 2011. Ecological and methodological factors affecting detectability and population estimation in elusive species. Journal of Wildlife Management 75:36-45.

WinsBerG, M. 1990. Florida Weather. University of Central Florida Press, USA.

Worton, B. 1987. A review of models of home range for animal movement. Ecological Modelling 38:277-298.

Accepted: 25 May 2019.

Published online: 26 August 2019. 